\title{
The Role of Spatial Analysis in Detecting the Consequence of the Factory Sites : Case Study of Assalaya Factory- Sudan
}

\author{
Amar Sharaf Eldin Khair ${ }^{1, *}$, Purwanto ${ }^{2}$, Henna RyaSunoko ${ }^{3}$, Omer Adam Abdullah ${ }^{4}$ \\ ${ }^{1}$ Lecturer at Omdurman Is lamic University, Geography Department, Omdurman city - Sudan \\ ${ }^{2}$ School of Postgraduate Studies, Diponegoro University, Semarang-Indonesia \\ ${ }^{3}$ Diponegoro University, Pharmacy Faculty, Semarang - Indonesia \\ ${ }^{4}$ Dean of art faculty, Omdurman Is lamic University, Omdurman city - Sudan
}

\begin{abstract}
Spatial analysis is considered as one of the most important science for identifying the most appropriate site for industrialization and also to alleviate the environmental ramifications caused by factories. This study aims at analyzing the Assalaya sugarcane factory site by the use of spatial analysis to determine whether it has ramification on the White Nile River. The methodology employed for this study is Global Position System (GPS) to identify the coordinate system of the study phenomena and other relative factors. The study will also make use Geographical Information System (GIS) to implement the spatial analysis. Satellite data (LandsatDem- Digital Elevation Model) will be considered for the study area and factory in identifying the consequences by analyzing the location of the factory through several features such as hydrological, contour line and geological analysis. Data analysis reveals that the factory site is inappropriate and according to observation on the ground it has consequences on the White Nile River. Based on the finding, the study recommended some suggestions to avoid the aftermath of any factory in general. We have to take advantage of this new technological method to aid in selecting most apt locations for industries that will create an ambient environment.
\end{abstract}

\section{Introduction}

The spatial analysis in this paper is emphasizes on the spatial elaboration for the factory site by several element using Global Position System (GPS) , Geographical Information System (GIS) and satellite data, making way for spatial interpretation of the factory potential zones. It has the ability to decide whether the factory location is suitable for the industrial process through special techniques. It will be elaborated in data analysis. It also has potential to find the affinity between Assalaya factory location and water resources-white Nile River and human settlement. The study will further illustrate the potential aftermath affected by the factory through analyzing the data by GIS technique, [1].

The GIS technique is considered as one of the important scientific technology that is recently in use as decisionmaker for selecting compatible location for industries and has ability to predict the future ramification as well as the influence by the factories through special techniques because it can be one of the scientific technological

Innovation which has ability to put scientific research findings into practice,[2].

The use modern technology with different techniques like Spatial Analysis and Digital Elevation Model (DEM) is the best way of selecting the right position of factories to avoid consequences caused by the factory production which has massive impact on water resources. So if factories are well-sited will bring forth both economic and environmental benefit especially in recent case of rapid population growth,[3].

Digital Elevation Model (DEM) is suitable to exhibit the continuous change of the earth topography. It is the basic data source for terrain analysis and spatial applications. It can be used for studies that are related to science and engineering. The function of the DEM is supported by the widespread availability of digital topographic data,[4].

There are significant reasons for the selection of this topic and choosing Assalaya factory. In relation to the selection of this topic, it has been observed that factory wastewater is discharged into White Nile River. The White Nile River is considered the main branch of River Nile and the fundamental source of drinking water in Sudan in general. This being the specific area under study, there arise the need to emphasize on the role and ability of Spatial Analysis to select compatible location of factories to secure human life from the consequences from the factories and also to conserve the environment and the realization of the economic efficiency as well.

Assalaya Factory is being chosen for this study because the factory has been allocated in an environment that is inappropriate and complained by citizens that stay around this area, where some people have been suffering as a result of sugar cultivation production output. It has

* Corresponding author: $\underline{\text { amar77600@gmail.com }}$ 
brutal consequences which affects the ecology, drinking water, air and the arable land. Furthermore, social impacts such as stinky smell, respiratory diseases, unsafe drinking water and the likes has caused the relocation of neighborhoods and villages.

The main purpose of the study is to eliminate and reduce the industrial wastewater which has significant role in polluting drinking water and endangering living organisms inside it. Through persuasion of the stakeholder and owners of industries and community participation, this cause can be properly addressed. This study also aims to emphasize the ability of Spatial Analysis in selecting the right position for any kind of industry through GIS software and arc toolbox window.

\section{Material and Method}

\subsection{Study sites}

Assalaya is located in Assalaya locality- White Nile State- Sudan between Longitude 33:33:10 West 32:58:52 East and, latitude 13:12:45 South 23:58:40 North. It is bordered by Aljazeera State and El jabalian in the north direction. To the south are Rabak and Knana cities. Sennar State, White Nile River and kosti city are to its west as it is seen in figure 1 . While the Assalaya factory is sited between Longitude 32:43:15 West and 32:45 East either the latitude between 13:14:40 south and 13:15:50 north. Its sugarcane fields spread over from east to west in $25 \mathrm{~km}$ and $12 \mathrm{~km}$ from north to south. The distance between the factory and the White Nile River is $8,5 \mathrm{~km}$ and the distance to the residential community is $2 \mathrm{~km}$ as seen in figure 1 .

\subsection{Study Type}

The study topic analyzes the sugar factory location and identifies whether its location is appropriate in order to prevent its ramification on the nearby society. Geospatial Information System will be used through spatial analysis function for the study. This study uses Global Positioning System (Ground survey), interviews and observation to get primary data. Also data will be collected from the field and secondary data as Satellite data DEM of the study area, has also been included in this study.

\subsection{Data Collection and Acquisition}

The study requires two kinds of data to realize its target and it includes secondary data which are; satellite data image represented in land sate Dem and GIS software to analyze the factory location as hydrological, contour line, slopping and geological analysis. Primary data include the data collected from the following methods; Observation, Global Positioning System GPS and the use of interviews.

\subsection{Data Analysis}

This study relies on landsat DEM that has been processed by GIS software program to analyze the data and to achieve the results as obvious in the study title. The study is confined on specific tools in the GIS program found in arc tools box. Overall, the study will analyze the slope map to find the slope direction of the factory position and hydrological analysis to determine whether the factory location is in runoff of the water and also geological map to investigate the geological location of the factory area. Lastly, contour line map for the study area with two meter interval will be used to identify the factory land level.

\section{Results:}

Through analysis, the contour line which had been figured out by GIS software which is processed via Arc tools box window. The purpose of that is to find out how far the factory location is suitable for the industrial production from the river. In evaluating the consequences on the water resource (White Nile River), the study found that the Contour lines have retreated towards the Nile reaching to 909 in the study phenomena and it has further declined to 779. This finding is based on analysis of the contour map of study area with interval 2 meters to determine the decline of contour line as seen in Figure 2.

Depending on the hydrological analysis for the factory location that has been analyzed based on land sate DEM and special techniques as identifying the study area, through the contour line and the hydrology, the study found that the factory location is located in water catchment area - valleys, lagoon- those are runoff toward White Nile River. Indicated in Figure 3.

Through analysis with the geological map of the study area, the study found that the industrial production site is within Ancient River Sedimentary adjacent to Modern River Sedimentary and Sediments of the Umm Ruwaba Formation. Meanwhile, the agriculture production the (sugarcane) is located in Ancient River Sedimentary, Umm Ruwaba Formation and the Nubian Sandstone as seen in Figure 4.

\section{Discussion}

The study through checking of the contour line indicates that the location of the factory is inappropriate because of the proximity in contour lines, where it declines subsequently in measures of909, 868,861, 807 till779. The contour indicates that, the smaller the vertical separator, the more the contour lines converge, [5]. Because contour successfully separate and identify the different objects and have been applied to many different applications, it is have many different approaches for detecting the location which have been developed and could be broadly used,[6]. 


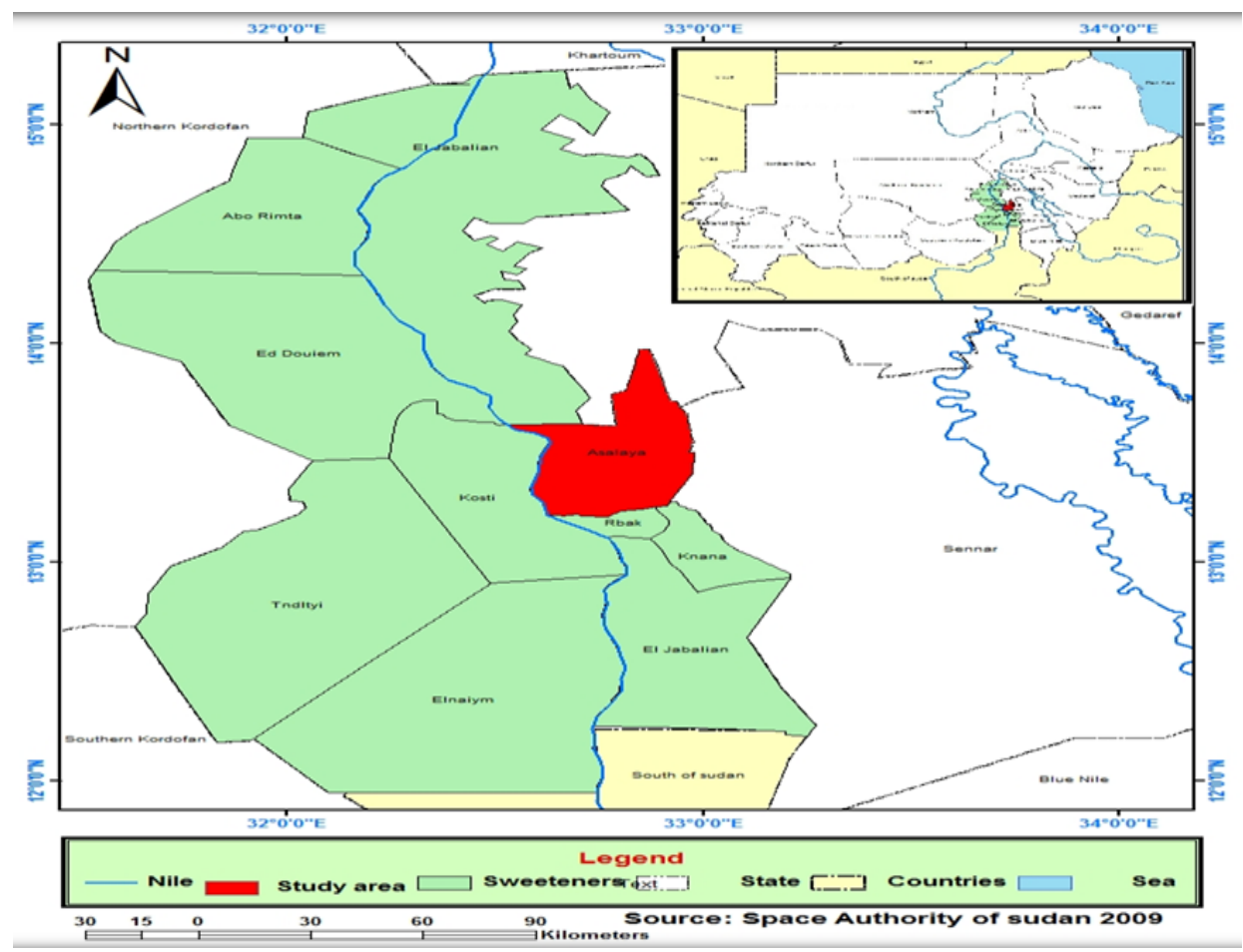

Fig. 1. Study sites

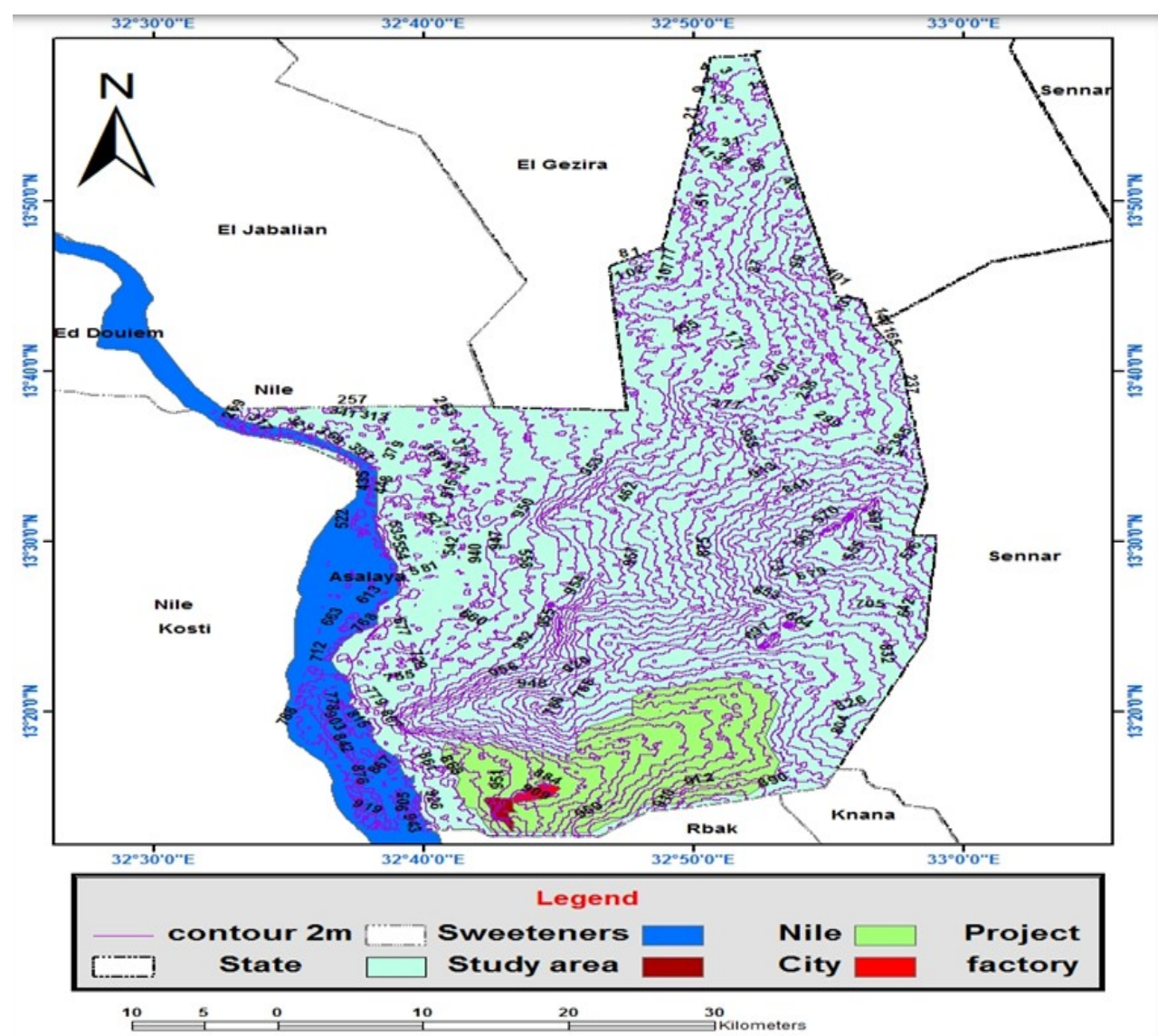

Fig. 2. Location Contour map 
The direction of the valleys and water flow have been shown in fig. 3 . To emphasize and prove that the study has selected two-meter contour to investigate the magnitude of the convergence in recognizing the factual and authentic way of flow. So the retreat of the contour line indicates that the direction of flow of the river. Based on the Geometry studies. It is wrong to set up factories in inappropriate position, because it may aggravate the condition as it creates phenomenon such as water pollution particularly in the white Nile river for instance as we become conscious of the study area and Sudan in general will rely on it for daily drinking. Not only is the White Nile River considered as the main source of water supply to several countries after joining with Blue Nile at Khartoum city. At this point, the emphases on how important the water resource that has been disturbed by the sugar factory is really realised. To avoid the ramification of it, it is better we keep proper planning in implementing projects, especially projects that have aftermath on ambient environmental resources.It is better if we built our ideas on geometry and other modern science because geometry constitutes the shape of the object and Physics imposes the constraints in how the shape of the object can contrast over time, [7].

The Hydrological analysis is done via satellite data DEM by GIS processing using several step which are; first, fill the Watercourses till the study area is flat and facilitate the water flow direction calculations, all of these process are done by GIS Arc Map $\rightarrow$ Arc tools box $\rightarrow$ Spatial analysis tools $\rightarrow$ Hydrology $\rightarrow$ Fill. Secondly; cutting the basin area done by Arc tools box $\rightarrow$ Spatial analysis tools $\rightarrow$ extract $\rightarrow$ clip hydrological models has become one of the fundamental tools that is widely used to identify such matters [8], through both processes appears that the study area had been situated in the catchment area which descends from the north-east direction and crosses the study area westward way downstream into the White Nile River at South-west in tree-delta form which indicate the location is not fit for establishing any kind of factory due to the valleys and rivers that runoff on it, it is likely to pollute the Nile water by the agricultural and industrial waste (pollutant).

The geological result found confirms that part of the factory area is situated in Ancient River Sedimentary and other parts in Sediments of The Umm Ruwaba Formation which indicates that the factory area in Agricultural production belt as well as it's sediment area which has created several Lagoons and valleys as seen in hydrological Fig 3. Establishing factories in these sites may infiltrate and percolate the industrial wastewater into groundwater and thus definitely connected with the Nile River (approximately $2 \mathrm{~km}$ between the river and the factory within Sedimentary area) therefore the factory needs industrial re-planning, it is better if it is set up in basement complex.

Overall, through analysis the collected data emphasizes that, it is inappropriate to establish any kind of industry in the research area. Besides, confirmation also comes from the conducted interviews at the study area, that the factory inflicts so much harm on the water resource which has changed the water quality by way of colour, bad smell, mutilation and malformation of some kind of fishes, [9].These effects have to a large extent had adverse bearing on many who reside near to the factory resettle to other places,[10].Through the observation, it turns out that the wastewater that comes from sugarcane irrigation and the operation have consequences on citizens'arable lands due to the slope, contour, hydrological and geological factors.

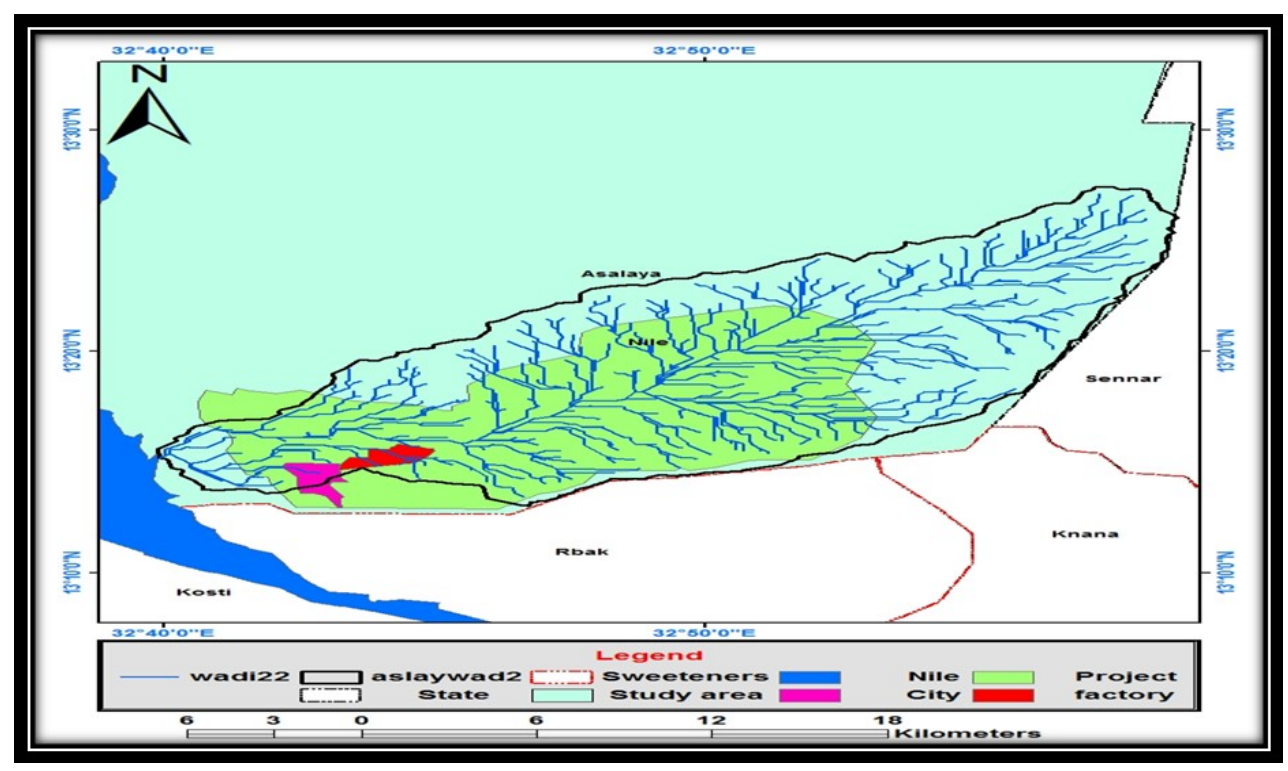

Fig.3. Hydrological map 


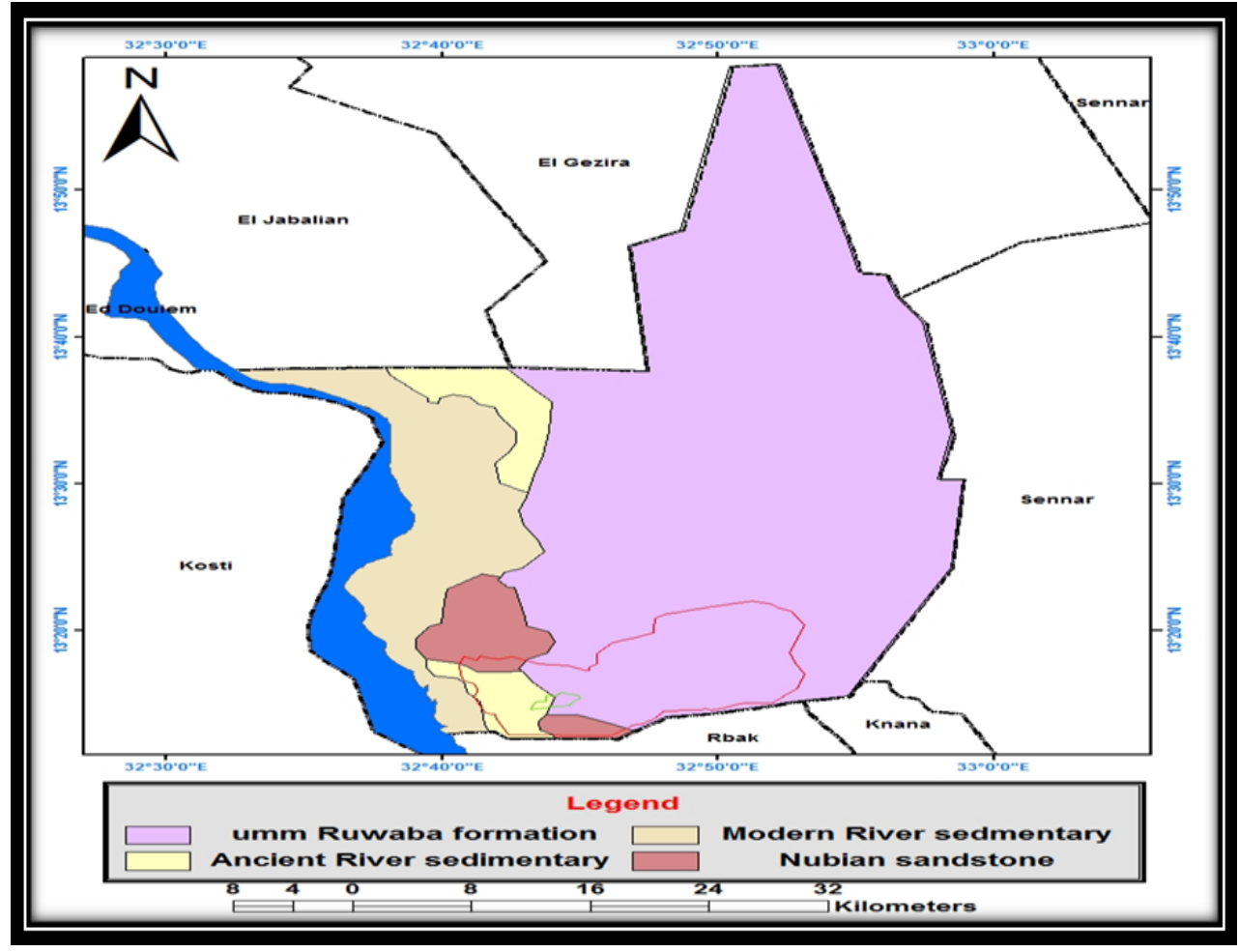

Fig.4. Geological map

\section{Conclusion and Suggestion}

The study concludes that all the study parameters that have been checked reveal that the factory location is inappropriate. The contour map data with Vertical separator2 Meters prove that via the retreat in contour lines subsequently 909, 868,861, 807 and till779. The hydrological map confirms that the area is located in water catchment area. The geological map has the same logic because the area is still within the Ancient River Sedimentary, and other part in Sediments of The Umm Ruwaba Formation. Based on the conclusion, the study suggests some recommendations for establishing any kind of developmental projects. Siting of factories such as that of Assalaya should be properly planned and thought of before putting up its structures. The Sudanese government and other responsible stakeholders should make and implement entrenched laws that will ensure that an industry like the aforementioned is well planned and situated. It is better if we use and follow modern techniques and technology such as environmental impact assessment (EIA), strategic environmental assessment(SEA) and Remote sensing and geographic information systems (RS\&GIS) in order to prevent the adverse effects but rather strengthen the scientific aspects.

\section{Acknowledgments}

First of all, the author would like to express heartfelt gratitude to his family for bringing him up from cradle to this stage. Secondly, he accords much appreciation to his supervisors namely Prof. Purwanto and Dr. Henna Rya Sunoko for guiding him through this dissertation. Also, a big thank you to the Sudanese Higher Education and Omdurman Islamic University for supporting this project. Sincere gratitude also goes to prof Saleh hasab Al Rasul, Dr. Omar Adam, Dr.Elyas Mansour, Mr. Abdullahabkar and Samuel Anderson for the incredible academic support. Thank you all of you for the input that contributed in making sure we are where we are today. Furthermore to the Lecturers at Doctoral Program of Environmental Science- School of Postgraduate Studies, Diponegoro University for endured the sacrifices in making everything is possible.

\section{References}

1. A.Wadood, A. Dewan, AOSI, RP. J. E 48, 104-111, P3,(2016).

2. Taylor. Francis, GIS for sustainable development, International Standard Book Number-10: 0-84933051-3 (Hardcover), P 6-7, (2006).

3. S. Sánchez, D. Athanassiadis, C. Martínez, E. Tolosana, J. Majada, E. Canga, GISMFOL,JCLP 9412, J. E 0959-6526, P3, (2017).

4. J.Thompson, J.Bell, C.Butler, DEM, JGEM100 , J. E 67-89, P1, (2001).

5. J ISPRS 62 93-103, P 94, (2007).

6. X. Wanga, C.Wei, K.Xianga, W. Chenb A Zhejiang, , J.VCIR, J. E 2022, P2, (2017).

7. R.Verdu'-Monedero, J. Morales-Sanchez, L. Weruaga, CAOAC,J.VCIR, J. E 26 1118-1128, P 1119,(2008).

8. R. Turcotte, J. Fortin, A.Rousseau, S. Massicotte, J.Villeneuve Institut, DOFTDS, J.H, J. E $240225-$ 
242,P3, (2001).

9. A. Ahmed, Interview with a fisherman, Al JazeeraAba city, (2017).
10. O. Mohammed, Interview with seiner citizen, Assalaya city, (2017). 